\title{
Self-Assembly of 2D Gold Nanoparticle Superlattice in a Polymer Vesicle Layer Driven by Hydrophobic Interaction
}

Jong Dae Jang ${ }^{1,2}$, Moongi Bae ${ }^{3}$, Changwoo Do ${ }^{4}$, Soo-Hyung Choi ${ }^{5}$, Joona Bang², Young Soo $\mathrm{Han}^{1}$, and Tae-Hwan $\mathrm{Kim}^{3 *}$

${ }^{1}$ Neutron Science Division, Korea Atomic Energy Research Institute, 1045 Daedeok-daero, Yuseong-gu, Daejeon, 34057, Republic of Korea

${ }^{2}$ Department of Chemical and Biological Engineering, Korea University, 145 Anam-ro, Sungbuk-gu, Seoul, 02841, Republic of Korea

${ }^{3}$ Department of Quantum System Engineering, Jeonbuk National University, 567 Baekjedaero, Deokjin-gu, Jeonju, 54896, Republic of Korea

${ }^{4}$ Biology and Soft Matter Division, Neutron Sciences Directorate, Oak Ridge National Laboratory, Oak Ridge, Tennessee, 37831, United States

${ }_{5}^{5}$ Department of Chemical Engineering, Hongik University, 94 Wausan-ro, Mapo-gu, Seoul, 04066, Republic of Korea

*Corresponding Author: taehwan@jbnu.ac.kr

This PDF file includes:

Figures S1 to S4

Tables $\mathrm{S} 1$ to $\mathrm{S} 2$ 
Initiation

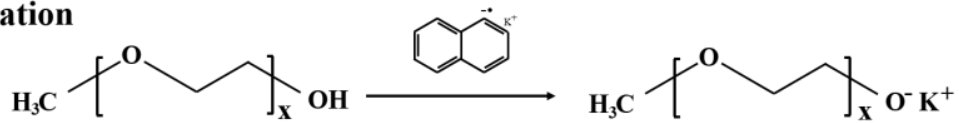

Propagation<smiles>CC(C)OCC([18OH])COCCOC(C)(C)OCC(C)OCC1CO1</smiles>

Termination

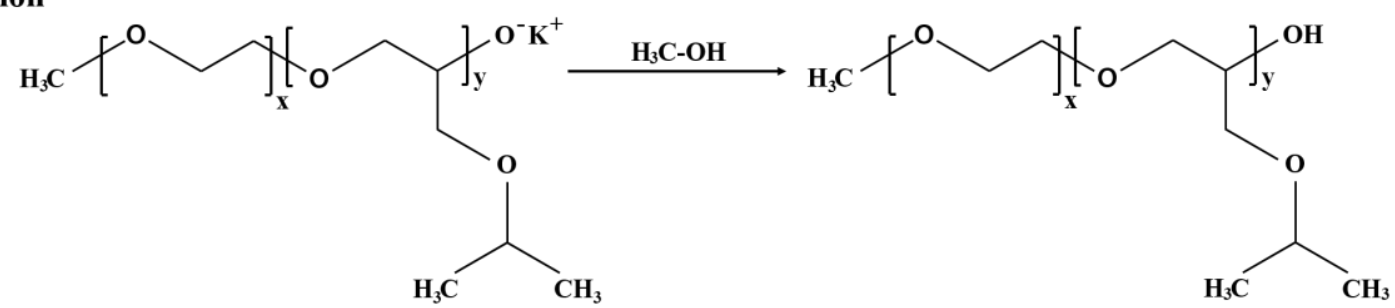

Figure S1. Synthes is of the $P\left(E_{x}-b-P G_{y}\right)$ diblock copolymer. 
(a)

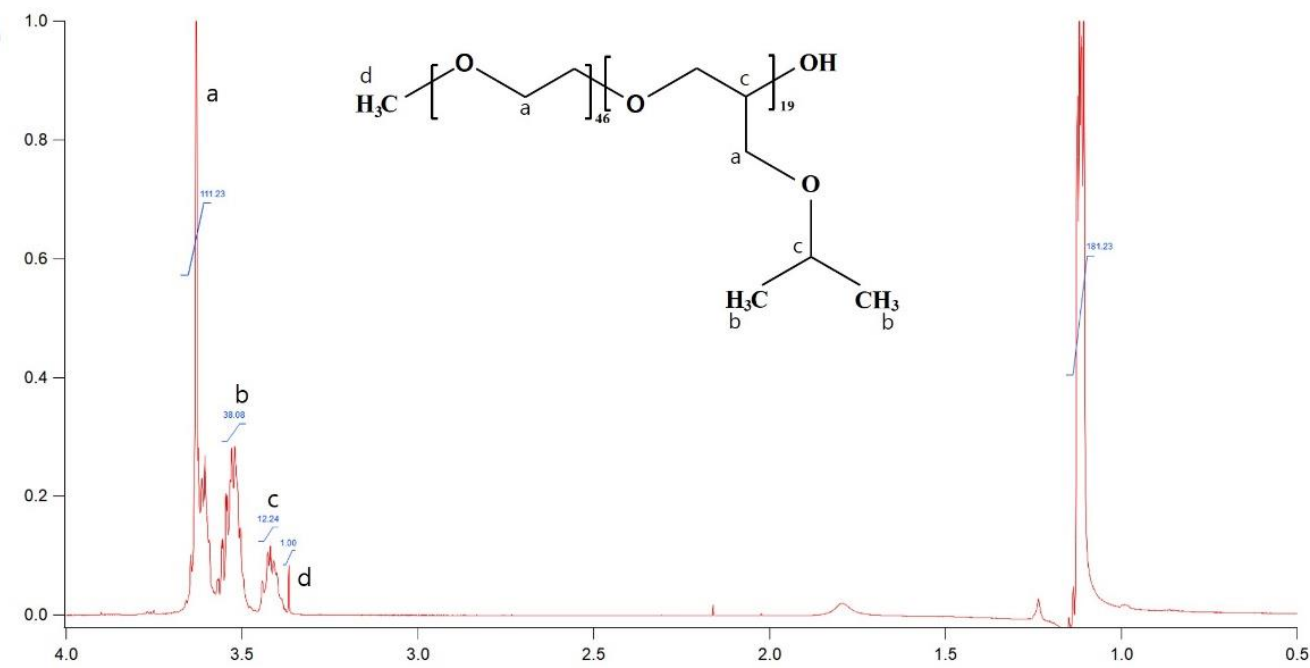

(b)

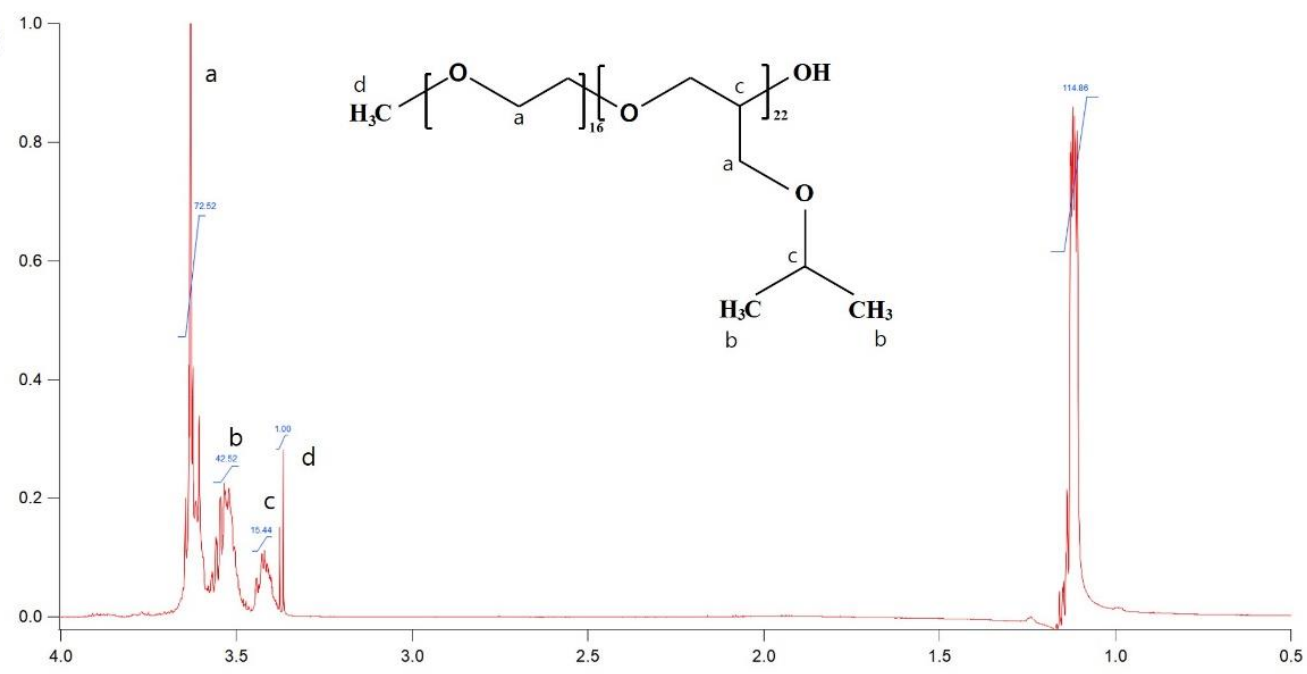

Figure S2. ${ }^{1} \mathrm{H}-\mathrm{NMR}$ spectra of the $\mathrm{P}\left(\mathrm{EG}_{\mathrm{x}}-b-\mathrm{PGE}_{\mathrm{y}}\right)$ diblock copolymer. (a) $0.75 \mathrm{~K}-2.35 \mathrm{~K}$ $\mathrm{P}\left(\mathrm{EG}_{\mathrm{x}}-b-\mathrm{PGE}_{\mathrm{y}}\right)$ diblock copolymer and (b) $2 \mathrm{~K}-2 \mathrm{~K}$ P(EG $\left(\mathrm{EG}_{\mathrm{x}}-b-\mathrm{PGE}_{\mathrm{y}}\right)$ diblock copolymer.
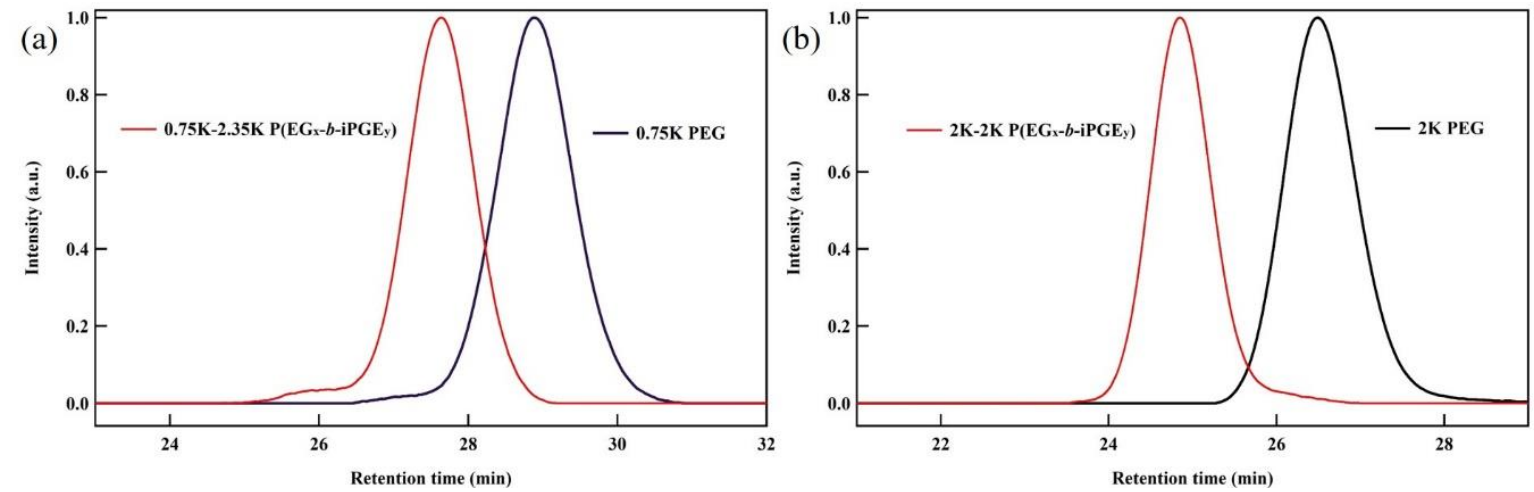

Figure S3. GPC traces of (a) $0.75 \mathrm{~K}$ PEG and $0.75 \mathrm{~K}-2.35 \mathrm{~K}$ P(EG $\left.\mathrm{EG}_{\mathrm{x}}-b-\mathrm{PGE}_{\mathrm{y}}\right)$ diblock copolymer and (b) $2 \mathrm{~K}$ PEG and $2 \mathrm{~K}-2 \mathrm{~K}$ P(EG $\left(\mathrm{EG}_{\mathrm{x}}-b-\mathrm{PGE}_{\mathrm{y}}\right)$ diblock copolymer in dimethylformala mide 
$(\mathrm{DMF})$

(a)

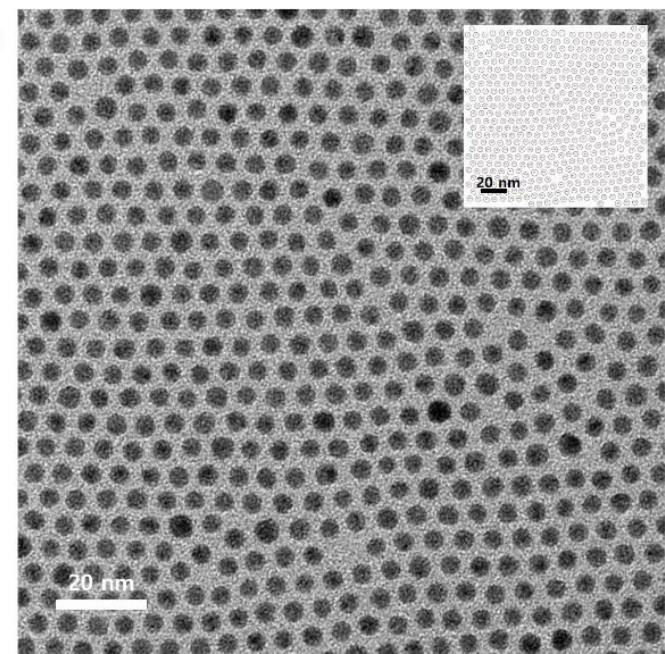

(b)

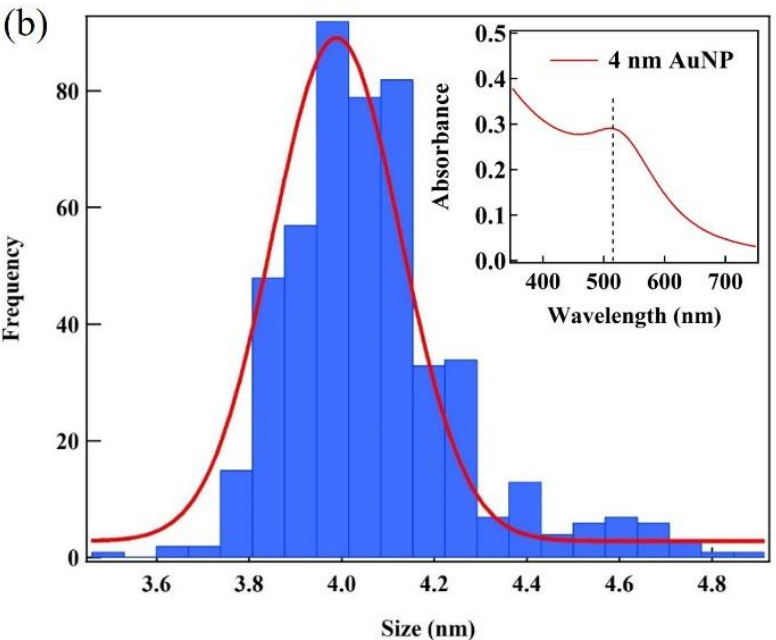

Figure S4. Trans mis s ion electron micros copy (TEM) analys is of the synthe sized AuNPs.

(a) TEM image (The average size is $4.00 \mathrm{~nm}( \pm 0.20 \mathrm{~nm})$, and the polydispersity is 0.05.$)$ and

(b) size distribution of the gold nanoparticles (AuNPs). The inset in (b) shows the ultravioletvisible (UV-vis) spectrum of the pristine AuNP.

(a)

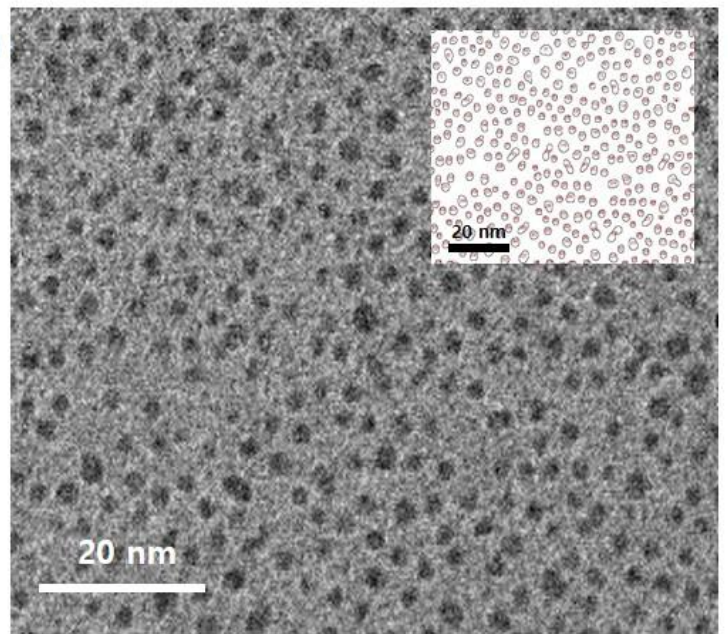

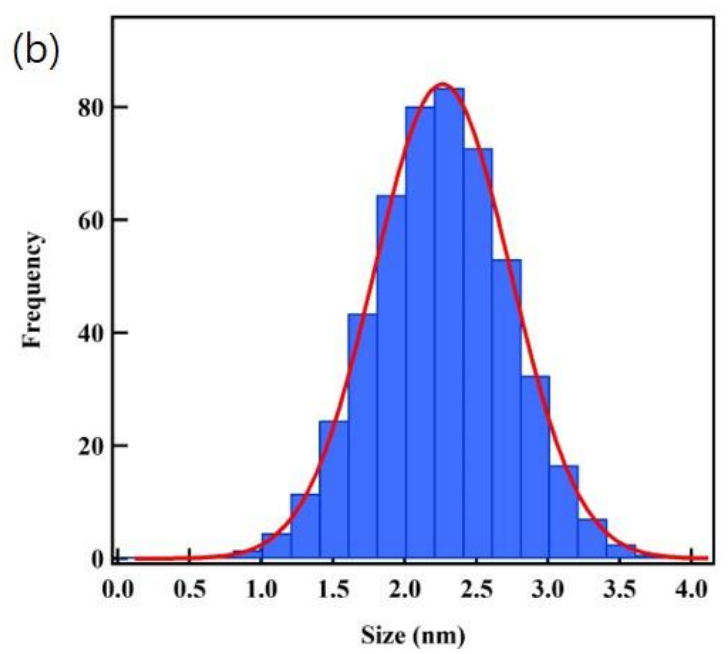

Figure S5. Trans miss ion electron micros copy (TEM) analys is of the synthes ized AuNPs.

(a) TEM image (The average size is $2.15 \mathrm{~nm}( \pm 0.47 \mathrm{~nm})$, and the polydispersity is 0.22 .) and (b) size distribution of the gold nanoparticles (AuNPs). 

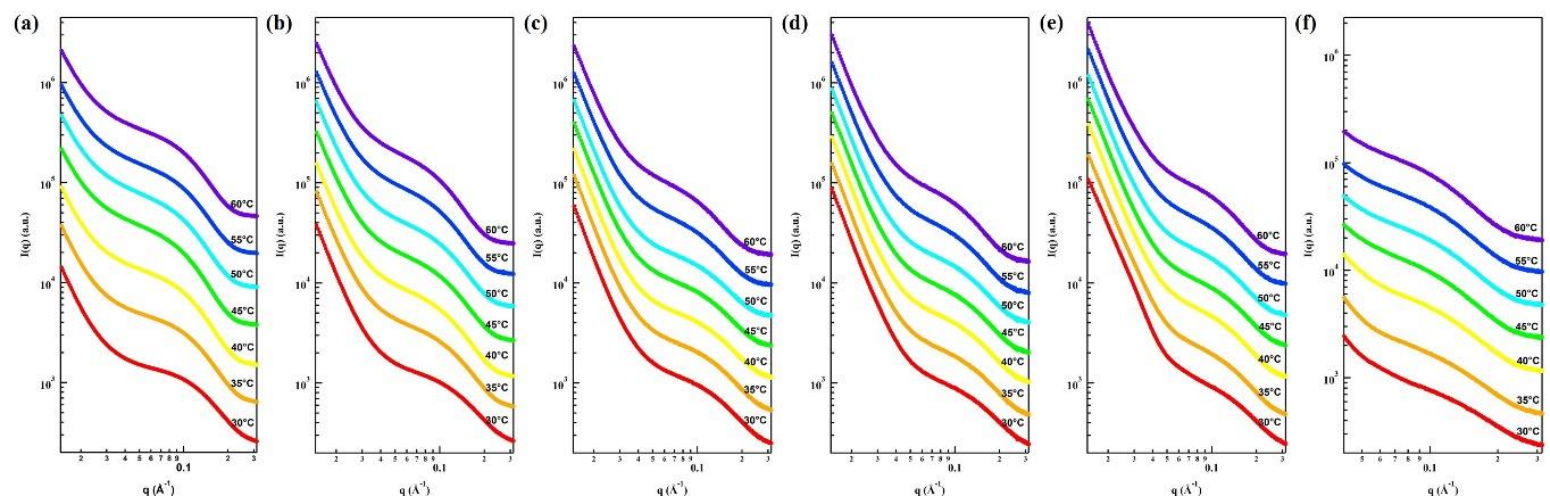

Figure S6. The SAXS experiments on various temperatures of the $2.15 \mathrm{~nm} A u N P-P\left(\mathrm{EG}_{\mathrm{x}}-b-\right.$ iPGE $\left.{ }_{y}\right)$ mixtures. (a) is the $2.15 \mathrm{~nm}$ AuNPs- $\mathrm{P}\left(\mathrm{EG}_{46}-b-\mathrm{PGE}_{19}\right) / \mathrm{P}\left(\mathrm{EG}_{16}-b-\mathrm{PGE}_{22}\right)(\mathrm{P}(46-19)$ $0.1 \% / \mathrm{P}(16-22) 0.0 \%$ ) mixture. (b) is the $2.15 \mathrm{~nm}$ AuNPs-P(46-19) $0.1 \% / \mathrm{P}(16-22) 0.1 \%$ mixture. (c) is the $2.15 \mathrm{~nm}$ AuNPs-P(46-19) $0.1 \% / \mathrm{P}(16-22) 0.2 \%$ mixture. (d) is the $2.15 \mathrm{~nm}$ AuNPs-P(46-19) $0.1 \% / \mathrm{P}(16-22) 0.3 \%$ mixture. (e) is the $2.15 \mathrm{~nm}$ AuNPs-P(46-19) $0.1 \%$ / $\mathrm{P}(16-22) 0.4 \%$ mixture. (f) is the $2.15 \mathrm{~nm}$ AuNPs- $\mathrm{P}(46-19) 0.1 \% / \mathrm{P}(16-22) 0.5 \%$ mixture.
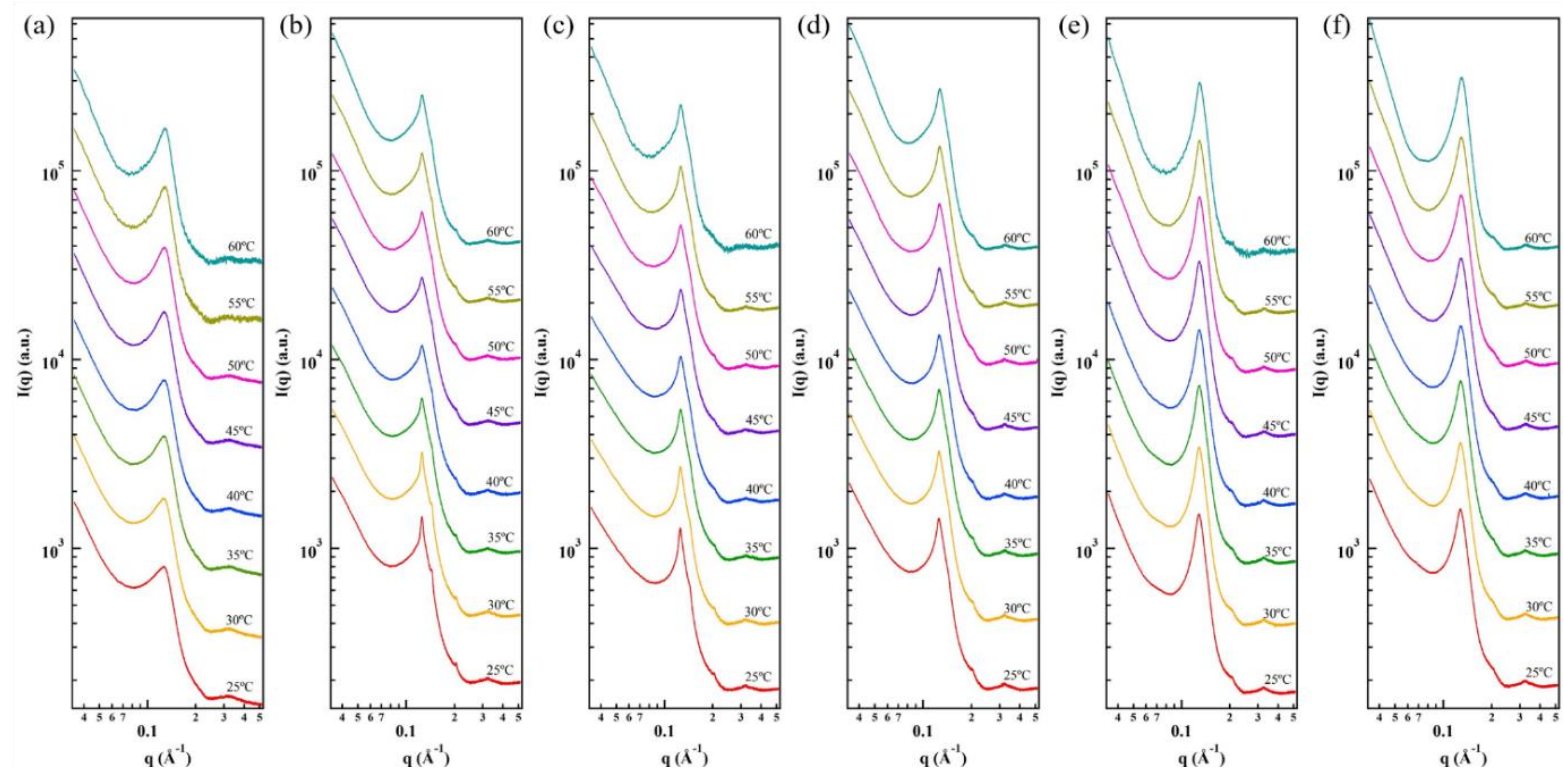

Figure S7. The SAXS experiments on various temperatures of the AuNP-P(EG $\left.-b-\mathrm{PGE}_{\mathrm{y}}\right)$ mixtures. (a) is the AuNPs-P(EG $\left.\mathrm{EG}_{46}-b-\mathrm{PGE}_{19}\right) / \mathrm{P}\left(\mathrm{EG}_{16}-b-\mathrm{PGE}_{22}\right)(\mathrm{P}(46-19) 0.1 \% / \mathrm{P}(16-22)$ $0.0 \%$ ) mixture. (b) is the AuNPs-P(46-19) $0.1 \% / \mathrm{P}(16-22) 0.1 \%$ mixture. (c) is the AuNPs$\mathrm{P}(46-19) 0.1 \% / \mathrm{P}(16-22) 0.2 \%$ mixture. (d) is the AuNPs- $\mathrm{P}(46-19) 0.1 \% / \mathrm{P}(16-22) 0.3 \%$ mixture. (e) is the AuNPs-P(46-19) $0.1 \%$ / $\mathrm{P}(16-22) 0.4 \%$ mixture. (f) is the AuNPs-P(46-19) $0.1 \% / \mathrm{P}(16-22) 0.5 \%$ mixture. 
Table S1. Scattering length densities

\begin{tabular}{cc}
\hline Molecule & $\begin{array}{c}\text { Scattering Length Density (SLD) } \\
\left(\times 10^{-6} \AA^{-2}\right)\end{array}$ \\
\hline \hline Poly(Ethylene Oxide) (PEO) & 0.419 \\
\hline iso-Propyl Glycidyl Ether (iPGE) & 0.317 \\
\hline Gold Nanoparticle (AuNP) & 4.667 \\
\hline$D_{2} O$ & 6.335 \\
\hline
\end{tabular}


Table S2. The information of the vesicle core and layer calculated by model fitting. The vesicle formed by (a) $\mathrm{P}(46-19) / \mathrm{P}(16-22)$ mixture, and (b) AuNP- P(46-19) / P(16-22) mixture.

\begin{tabular}{cccc}
\hline (a) & \multicolumn{3}{c}{$\mathrm{P}(46-19) / \mathrm{P}(16-22)$ mixture } \\
$\begin{array}{c}\text { Polymer } \\
\text { concentration }\end{array}$ & Core diameter $(\mathrm{nm})$ & $\begin{array}{c}\text { Thickness of the } \\
\text { polymer outer layer } \\
(\mathrm{nm})\end{array}$ & $\begin{array}{c}\text { Thickness of the } \\
\text { polymer inner layer } \\
(\mathrm{nm})\end{array}$ \\
\hline $\begin{array}{c}\mathrm{P}(46-19) 0.1 \% / \\
\mathrm{P}(16-22) 0.0 \%\end{array}$ & - & - & - \\
\hline $\begin{array}{c}\mathrm{P}(46-19) 0.1 \% / \\
\mathrm{P}(16-22) 0.1 \%\end{array}$ & 133.1 & 8.0 & 3.2 \\
\hline $\begin{array}{c}\mathrm{P}(46-19) 0.1 \% / \\
\mathrm{P}(16-22) 0.2 \%\end{array}$ & 145.9 & 6.9 & 3.1 \\
\hline $\begin{array}{c}\mathrm{P}(46-19) 0.1 \% / \\
\mathrm{P}(16-22) 0.3 \%\end{array}$ & 149.6 & 5.7 & 2.9 \\
\hline $\begin{array}{r}\mathrm{P}(46-19) 0.1 \% / \\
\mathrm{P}(16-22) 0.4 \%\end{array}$ & 151.7 & 5.2 & 2.8 \\
\hline $\begin{array}{r}\mathrm{P}(46-19) 0.1 \% / \\
\mathrm{P}(16-22) 0.5 \%\end{array}$ & 151.7 & 5.2 & 2.8 \\
\hline
\end{tabular}




\begin{tabular}{|c|c|c|c|c|c|}
\hline \multirow{3}{*}{$\begin{array}{c}\text { (b) } \\
\\
\begin{array}{c}\text { Polymer } \\
\text { concentration }\end{array}\end{array}$} & \multicolumn{5}{|c|}{ AuNPs-P(46-19) / P(16-22) mixture } \\
\hline & \multicolumn{3}{|c|}{ With AuNPs (dominated > 97 \%) } & \multicolumn{2}{|c|}{ Without AuNPs } \\
\hline & $\begin{array}{l}\text { Core diameter } \\
(\mathrm{nm})\end{array}$ & $\begin{array}{c}\text { Thickness of the polymer } \\
\text { outer layer }(\mathrm{nm})\end{array}$ & $\begin{array}{l}\text { Thickness of the } \\
\text { gold inner layer }(\mathrm{nm})\end{array}$ & $\begin{array}{l}\text { Core diameter } \\
(\mathrm{nm})\end{array}$ & $\begin{array}{l}\text { Thickness of the } \\
\text { polymer bilayer }(\mathrm{nm})\end{array}$ \\
\hline $\begin{array}{c}\mathrm{P}(46-19) 0.1 \% / \\
\mathrm{P}(16-22) 0.0 \% \\
\end{array}$ & - & - & - & - & - \\
\hline $\begin{array}{l}\mathrm{P}(46-19) \quad 0.1 \% / \\
\mathrm{P}(16-22) 0.1 \%\end{array}$ & 132.7 & 5.1 & 3.6 & 129.2 & 10.1 \\
\hline $\begin{array}{c}\mathrm{P}(46-19) 0.1 \% / \\
\mathrm{P}(16-22) 0.2 \% \\
\end{array}$ & 152.0 & 4.9 & 3.6 & 143.0 & 9.8 \\
\hline $\begin{array}{c}\mathrm{P}(46-19) 0.1 \% / \\
\mathrm{P}(16-22) 0.3 \%\end{array}$ & 155.9 & 3.7 & 3.1 & 145.9 & 9.2 \\
\hline $\begin{array}{c}\mathrm{P}(46-19) 0.1 \% / \\
\mathrm{P}(16-22) 0.4 \% \\
\end{array}$ & 154.5 & 3.7 & 3.0 & 148.4 & 8.5 \\
\hline $\begin{array}{l}\mathrm{P}(46-19) 0.1 \% / \\
\mathrm{P}(16-22) 0.5 \%\end{array}$ & 167.6 & 3.4 & 2.8 & 150.6 & 8.3 \\
\hline
\end{tabular}

